\title{
Building blocks of consciousness: Revealing the shared, hidden depths of our biological heritage
}

\begin{tabular}{|c|c|}
\hline \multicolumn{2}{|c|}{$\begin{array}{l}\text { Authors: } \\
\text { Juri van den Heever }{ }^{1} \\
\text { Chris Jones }^{2}\end{array}$} \\
\hline \multicolumn{2}{|c|}{$\begin{array}{l}\text { Affiliations: } \\
{ }^{1} \text { Faculty of Science, } \\
\text { Department of Botany and } \\
\text { Zoology, Stellenbosch } \\
\text { University, Stellenbosch, } \\
\text { South Africa }\end{array}$} \\
\hline \multicolumn{2}{|c|}{$\begin{array}{l}{ }^{2} \text { Department of Systematic } \\
\text { Theology \& Ecclesiology, } \\
\text { Faculty of Theology, } \\
\text { Stellenbosch University, } \\
\text { Stellenbosch, South Africa }\end{array}$} \\
\hline \multicolumn{2}{|c|}{$\begin{array}{l}\text { Corresponding author: } \\
\text { Chris Jones, } \\
\text { chrisjones@sun.ac.za }\end{array}$} \\
\hline \multicolumn{2}{|c|}{$\begin{array}{l}\text { Dates: } \\
\text { Received: } 24 \text { Apr. } 2020 \\
\text { Accepted: } 14 \text { Sept. } 2020 \\
\text { Published: } 20 \text { Nov. } 2020\end{array}$} \\
\hline \multicolumn{2}{|c|}{$\begin{array}{l}\text { How to cite this article: } \\
\text { Van den Heever, J. \& Jones, } \\
\text { C., 2020, 'Building blocks of } \\
\text { consciousness: Revealing } \\
\text { the shared, hidden depths } \\
\text { of our biological heritage', } \\
\text { HTS Teologiese Studies/ } \\
\text { Theological Studies } \\
\text { 76(1), a6055. https://doi. } \\
\text { org/10.4102/hts.v76i1.6055 }\end{array}$} \\
\hline \multicolumn{2}{|c|}{$\begin{array}{l}\text { Copyright: } \\
\text { (C) 2020. The Authors } \\
\text { Licensee: AOSIS. This } \\
\text { is licensed under the } \\
\text { Creative Commons } \\
\text { Attribution License. }\end{array}$} \\
\hline \multicolumn{2}{|l|}{ Read online: } \\
\hline 回伍: & $\begin{array}{l}\text { Scan this QR } \\
\text { code with your } \\
\text { smart phone or } \\
\text { mobile device } \\
\text { to read online. }\end{array}$ \\
\hline
\end{tabular}

Human consciousness has been a hard problem for thousands of years and, in the course of time, variously interpreted and often too narrowly defined. As a result, the possibility of animal consciousness, sentience or even the possibility that animals can experience pain, received no, or very little, attention. Driven by the trope that animals lack the basic neural attributes to even experience pain, humans have seriously endangered the natural existence of untold multitudes of sentient organisms. However, humans are not the only conscious organisms on the planet, as suggested by a variety of research results, attesting to the fact that even lower vertebrates possess sentience and feel pain. Multiple research findings have now stressed the need for a phylogenetic approach to consciousness, which, in the long run, will have extensive theological implications. Succinctly put, these findings indicate that we live in a world of minds, and that only some of them are human.

Contribution: This article is part of a special collection that reflects fundamentally on the origin and evolution of the universe as well as what the future possibly might hold. It is based on historical thought and contemporary research. Different, conflicting sources are being interpreted, and the research approach is in line with the intersectional and interdisciplinary nature of this journal. We do not directly engage theology and religion, although the research and empirical data are underpinned by a moral imperative that cannot be avoided by theological and religious disciplines.

Keywords: Animal consciousness; Sentience; Cognition; Awareness; Neural biology; Nociception.

\section{Introduction}

The explanation of consciousness is one of the major unsolved problems of modern science. After several thousand years of speculation, it would be very gratifying to find an answer to it. (Crick \& Koch 1998:105)

Behind the debate about animal consciousness lurks an issue that many scientists would much rather avoid: what humanity does to animals. (De Waal 2019:242)

The aim of the article was to assess the evidence for consciousness in non-human life forms. It will be restricted to some of the most influential historical and contemporary arguments, conflicting human convictions as well as empirical data supporting the existence of consciousness in different forms of life.

We hope to sensitise humans in developing a responsible moral position with regard to the economic usage and insensitive treatment of life forms we often aggressively utilise as food items on such a massive scale.

Although we do not directly engage with theology and religion, the data generated by these investigations carry a moral imperative, which broadly involves theological and religious convictions.

\section{Historical overview}

Historically the subject of human consciousness casts a long shadow, representing a variety of often conflicting interpretations. Traditionally, consciousness has been seen as a uniquely human phenomenon, lacking in animals of any stripe.

Note: Special Collection entitled Challenging Building Blocks: The coherence of cosmological evolution, life, consciousness, morality and building the 21st century, sub-edited by Chris Jones (SUN) and Juri van den Heever (SUN). 
This is largely because of the towering influence of Aristotle. In his time and beyond he was acknowledged as an exceptionally gifted individual. Even Dante singled him out in the Inferno as '... il maestro di color che sanno ...' [master of the sapient throng] (Inferno IV:131). Thus his views on science and the natural world overshadowed those of his peers, in spite of the fact that the Democritean interpretation of natural phenomena '... represents, according to the philosophy adopted by the majority of modern scientists, the sound scientific attitude' (Montalenti 1974:4).

Greek philosophers differed in their approach to and understanding of the state of conciousness. Contrary to Pythagoras (c. 570-c. 495 BC), who advocated that humans and animals shared a similar kind of soul, the views of Aristotle (384-322 BC) prevailed. In his book, De Anima (The Soul) his discussion of the soul is confined to the physiological characteristics of the organism (Leroi 2014):

This to us is a very strange, even suspect, claim. 'Soul' is a word burdened with many meanings but none in modern science. Perhaps we would do better to abandon translation, but mere transliteration hardly helps matters at all. For us 'psyche' refers to mental states - in particular consciousness. To be sure, Aristotle does treat mental states in his book, but he treats them as physiology: The Cartesian problem of consciousness hardly arises. (p. 157)

For Aristotle then, the soul of living entities is the sum of its functional features. Because some of these features '... are more specific and apply just to humans' (Leroi 2014:159), they are sufficient to conclusively distinguish between humans and animals. This argued for rational souls in humans as opposed to mere instinctive behaviour in animals, as is reflected in his phylogenetic construct, the Great Chain of Being, with humans at the apex. Aristotle also subscribed to the view that animals were created for use by humans, and consequently Greek scientists freely practised live dissection of animals (Pinker 2011:553).

The influential medieval scholar Thomas Aquinas (1225-1274), amongst other lesser figures in medieval Christianity, (read Catholic Church) was largely responsible for the synthesis of Greek rationalism with Christian doctrine. His magnum opus the Summa Theologica is regarded as the acme of medieval, Christian philosophy (Gross 2009):

By the divine providence [animals] are intended for man's use ... hence it is not wrong for man to make use of them, either by killing or in any other way whatsoever. (p. 466)

Aquinas, taking a leaf out of Aristotle's book, appropriated the Great Chain of Being as the Scala Naturae, in which God was added at the apex. Thus, the medieval Catholic Church, with its wide ranging political powers, officially sanctioned the lack of souls in animals, and in this way, Aristotle's view was almost universally accepted in the West for 2000 years.

During the 17th century the French polymath René Descartes (1596-1650) (Kenny 1997:110) was influential in regarding animals, other than humans, to exhibit 'only reflex behaviours' (Blackmore 2018:42). 'Descartes wrote that animals were clockwork, so there was no one home to feel pain or pleasure' (Pinker 2011:553). His conviction that animals lacked souls, and could consequently be treated as automatons, meant that non-human life could be exploited and maltreated without consequence. Exploiting the natural resources of the planet in the way that we currently do is devoid of any moral justification, but reflects an anthropocentric worldview that reeks of prescriptive biblical attitudes, exacerbated by medieval theological convictions about non-human life, and which lasted, according to Gross (2009:466), at least in the United Kingdom, up to the latter half of the 19th century. Considering the treatment modern-day humans mete out to a variety of animals within the economic food chain, this attitude appears to still resonate in certain quarters.

\section{Contemporary debate Do animals exhibit conciousness?}

Arguments that non-human animals are not conscious therefore effectively doubles as apologetics for our treatment of animals. When the question of animal conciousness is under consideration, our guilt or innocence as a civilization for an enormous body of cruelty may hang in the balance. (Allan \& Tressman 2017; Stanford Encyclopedia of Philosophy n.p.)

The concept of animals being sentient or capable of experiencing positive or negative affective states has suddenly become, in the last 30 years, a topic of great interest to biologists. (Duncan 2006:11)

The question then of whether animals are consciousness, sentient or are able to experience pain is increasingly relevant in a world dominated by the unbridled, and in many ways draconian, exploitation of living natural resources for human benefit, as pointed out by Jacquet (2018:3).

Dennett (2018:372) chastised Chomsky (1976:281, 2014), because he unequivocally divides the human endeavour into solvable problems and unsolvable mysteries. This division acknowledges the problem-solving capacity of science in innumerable examples, and the fact that progress is being made in thousands of other problematic fields of endeavour. However, Chomsky believes that there are problems that are insolvable, and these he terms mysteries, with consciousness and free will at the apex of the list. The implication being that the human brain is an organ with obvious limits and cannot therefore explore beyond a certain capacity or it will encounter a cognitive boundary, beyond which it cannot go. McGinn (1991:3) had termed this as the point of cognitive closure. Dennett disagrees and points out that many of the problems that qualified as mysteries in the past have been solved on an increasing basis by the curiosity and inquisitiveness of scientists.

He correctly refers to the fact that different brains can cooperatively function as an extended neural network, overcoming the so-called cognitive closure of a single brain. In practice it works out that scientific articles on, for 
example, the complexities of Alpine geology or human evolution, can have as many as 35 authors and in certain medical disciplines an even longer list of contributors. It does not follow that all the authors are equally cognisant of every aspect of such multiauthored articles, but each contribution tends to extend the explanatory power and scientific reach of such projects, toppling mysteries and exposing further problems (Dennett 1993):

When we understand consciousness - when there is no more mystery - consciousness will be different, but there will still be beauty, and more room than ever for awe. (p. 25)

\section{Griffin and Speck (2004) pointed out that:}

$[E] x p e r i m e n t a l$ and observational data about the complexity and versatility of animal cognition have been reported and discussed extensively since the subject was reviewed in the first issue of this journal. (p. 5)

Consequently, consciousness in both animals and humans have been under investigation by a formidable contingent of researchers who do not always agree on whether animals are self-aware, aware of external objects or aware of something within themselves. Equally, assessments of human consciousness have variously described concepts such as executive control system of the mind, subjectivity, having a sense of self, sentience, qualia, awareness, the ability to experience or to feel and wakefulness (Blackmore 2018):

Yet the more biology we learn, the more obvious it is that we share not only anatomy, physiology and genetics with other animals but also systems of vision, hearing, memory and emotional expression. Could it really be that we alone have an extra special something - this marvelous inner world of subjective experience? (p. 42)

Allan and Tressman (2017, Stanford Encyclopedia of Philosophy) insisted that if the question of animal consciousness was to be solved it would have to be through an interdisciplinary approach, requiring data gathered by sound scientific techniques and not relying solely on philosophical explanations, as:

$[N]$ o amount of arm-chair pondering, conceptual analysis, logic, a-priori theory-building, trancendental inference or introspection will tell us whether a platypus, an iguana, or a squid (to take a few examples) enjoy a life of subjective experience - at some point we will have to learn something about the animals. (n.p.)

This would require information on behaviour, neurophysiology and phylogenetic relationships of a wide array of taxa. The reason why they favour an interdisciplinary aproach is because '... these questions are deeply philosophical as well, with epistemological, metaphysical and phenomenological dimensions'.

Dennett (1993:24) who has been accused of denying the existence of consciousness, believes '... that consciousness, like love and money, is a phenomenon that does indeed depend to a surprising extent on its associated concepts'. He expects that if some of these concepts are overthrown, whatever phenomena of consciousness that depend on them, will then be doomed to extinction (Dennett 1993):

If the concept of consciousness were to 'fall to science', what would happen to our sense of moral agency and free will? If conscious experience were 'reduced' somehow to mere matter in motion, what would happen to our appreciation of love and pain and dreams and joy? If conscious human beings were 'just' animated material objects, how could anything we do to them be right or wrong? These are among the fears that fuel the resistance and distract the concentration of those who are confronted with attempts to explain consciousness. (pp. 24-25)

This is a salient point because a good section of humanity has always been distrustful of evolutionary claims that we have evolved and therefore share kinship with ostensibly lesser creatures. However, Dennett is confident that the fears he lists are misguided, and to accept his scientific, materialistic theory would not be the end of the world.

\section{According to Griffin and Speck (2004):}

[C]onsciousness is the subjective state of feeling and thinking about objects and events. The word is most often taken to mean full-blown human thinking, although of course no animal attains more than a trivial fraction of the scope and versatility of human conscious thinking. (p. 6)

Many animals, however, exhibit what Natsoulas (1983:29) define as consciousness 3, 'the state or facility of being mentally conscious or aware of anything'. This has been 'called perceptual, primary or basic consciousness. However limited its content may be, such awareness is importantly different from unconscious cognition' (Griffin \& Speck 2004:6).

Griffin and Speck (2004:5) were of the opinion that the '... accumulation of strongly suggestive evidence increases significantly the likelihood that some animals experience at least simple concsious thoughts and feelings'. They (Griffin \& Speck 2004:5) also pointed out that ' $\mathrm{t}$ ] he term cognition is ordinarily taken to mean information processing in human and non-human central nervous systems that often leads to choices and decisions'.

\section{They (Griffin \& Speck 2004) further contend that although:}

$[E] x p e r i m e n t a l$ and observational data about the complexity and versatility of animal cognition have been reported and discussed extensively ... the possibility that nonhuman cognition is accompanied or influenced by consciouness has received relatively little attention, largely because many behavioral scientists have been extremely reluctant to consider nonhuman consciousness on the grounds that it is impossible to obtain objective evidence about subjective experiences.

In view of the confusions surrounding terms describing mental states, and despite the fact that some scientists feel that consciousness is a higher and more complex state than awareness, we will follow the common useage of aware and conscious as synonyms that describe subjective experiences. We will assume that these states or processes are produced by the functioning of living nervous systems and not something 
ethereal and different in kind from anything in the physical universe, as emphasised by Searle (2000). (p. 5)

Some scientists believe that consciousness cannot be scientifically investigated because it lacks a precise definition, a notion countered by Searle (2000) pointing out that in studying a confusing problem, all that is needed initially is a commonsense definition, for example:

'[C]onsciousness' refers to those states of sentience or awareness that typically begin when we wake from a dreamless sleep and continue through the day until we fall asleep again, die, go into a coma or otherwise become unconscious. (p. 559)

Broadly identifying the target of the project at the outset is sufficient to initiate the investigation, and as the research progresses, the definition can accordingly be modified.

Other researchers (Broom 2007) had proposed a more precise definition:

A sentient being is one that has some ability '... to evaluate the actions of others in relation to itself and third parties, to remember some of its own actions and their consequenses, to assess risks and benefits, to have some feelings, and to have some degree of awareness'. (p. 100)

Ever since Darwin expressed his views on consciousness, it has been conclusively shown by an extensive array of disciplines that phylogenetically we are part and parcel of the evolution of life on the third planet. It therefore appears self-evident that consciousness, just like the evolution of our moral disposition, as opposed to moral codes, which are culturally determined, also evolved (Van den Heever \& Jones 2019:8-14).

Against an evolutionary background it seems inconceiveable that consciousness, in its full complexity, was exclusively bestowed upon humans. It has been said that consciousness is a development of mind from unrecognisable to recogniseable, and consequently scientists have increasingly voiced the opinion that at least some, if not all, non-human species exhibit a form of consciousness. Claiming that consciousness or at the very least sentience is present in all or some non-human vertebrates, who are not able to verbalise their inner thoughts, clearly subsumes the position that a sound basis to establish sentience in animals is through scientific verification (Edelman 2003:5520; Searle 2000:568).

Neurobiologists have shown that the human brain evolved like any other organ in the body and lacks any ethereal components, as pointed out by Searle (2000:568) putting paid to the concept of res cogitans or 'thinking thing' proposed by Descartes. Thus, the proper study of the human condition, including the 'mystery' of consciousness should ideally be from an evolutionary perspective, which automatically includes all other life forms as well.

Consciousness, in the wider sense, also controversially includes researchers such as Margulis (2001:55) who noted that the evolutionary antecedent to the nervous system was 'microbial consciousness' and stated that the cellular components that led to the origin of the eukaryotic cell, via symbiogenesis, were already 'conscious', as well as Nagel (1997), a proponent of consciousness in plants.

\section{Human attitudes with respect to non-human life forms}

For a variety of reasons humans exhibit inconsistent attitudes towards other life forms, particularly with regard to the possible presence of sentience in non-mammalian vertebrates. Perhaps because of the closer phylogenetic link and a natural empathy towards juveniles, small furry endotherms with large expressive eyes are generally favoured above invertebrates and scaly ectotherms. In addition, it also makes life easier to consciously deny the existence of sentience in commercial food animals, or species considered vermin, in order not to confront the moral burden of mindlessly killing billions of possibly sentient creatures (Dawkins 1980):

We have only to think of various different sort of animals to show up our inconsistencies. There are demonstrations against killing baby harp seals, but there are no comparable campaigns to stop the killing of rats. Many people are quite happy to eat pigs or sheep but horrified by the idea of eating dogs or horses. (p. 150)

Humans are consciously and increasingly destroying some of the most important and diverse natural living systems on earth, whilst promoting the survival of selected monocultures, for example, wheat, canola, maize, rice and beef. There is a dire need, both moral and empirical, to rectify this situation and migitate our attitude towards all other forms of life. The deeply felt conviction that all of humanity should, at the very least, subscribe to a binding declaration stating that all life forms on the planet deserve to be treated with respect, probably has more than a passing congruity with the act of wishing upon a shooting star.

De Waal (2019:245-246) proposed three reasons why we should respect all forms of life, namely the dignity inherent in all things living, the interest all life forms have in their exsistence and survival, and lastly, sentience and the capacity for suffering.

We appear to be universally selective in the way we subjectively bestow dignity upon different life forms, favouring flowering plants above weeds and antelopes above snakes. For De Waal this attitude yet again raises the spectre of the now defunct Scala Naturae, suggesting that the only objective criteria might be an organism's intelligence and its age.

Interest in staying alive is a universal feature of all life. To survive as individuals, and ultimately as a species, organisms require sufficient nutrition as a means to procreate. This may not involve conscious decisions, as single-celled organisms clearly react to and avoid harmful substances without 
neurological assistance, and plants, in the same vein, release toxic chemicals against foragers and to warn conspecifics.

Sentience is defined as the capacity to experience, feel or perceive (De Waal 2019:246). In its widest sense, all organisms can then be regarded as sentient, including eukaryotic cells that strive to maintain homeostasis. The capacity to feel pain and to suffer has been demonstrated across the phylogenetic spectrum ranging from invertebrates to humans.

The capacity to suffer, especially in invertebrates and non-mammalian vertebrates, has been hotly contested. Dennet (1993) clearly stated on which side of the fence he found himself:

It follows - and this does strike an intuitive chord - that the capacity to suffer is a function of the capacity to have articulated, wide-ranging, highly discriminative desires, expectations, and other sophisticated mental states. (p. 449)

Others, like Damasio (1999), favoured a broader view:

It requires something not unlike perception in order to sense imbalance; it requires something not unlike implicit memory, in the form of disposition for an action, in order to hold its technical know-how; it requires something not unlike a skill to perform a pre-emptive or corrective action. If all this sounds to you like important functions of our brain, you are correct. The fact is, however, that I am not talking about a brain, because there is no nervous system inside the little cell. (p. 138)

Shapiro (2011:143), on the other hand, stated unequivocally: 'Living cells and organisms are cognitive (sentient) entities that act and interact purposefully to ensure survival, growth and proliferation'.

\section{Discussion of relevant emperical data attesting to sentience in all life forms \\ Invertebrates}

In neurological studies a distinction is recognised between pain and nociception. The latter refers to the capacity to detect noxious stimuli in a variety of invertebrate animals, including leeches and marine snails. The medical leech Hirudo medicinalis and sea slug are classic models for studying nociception. As nociceptors still function in decerebrate animals, their presence is not necessarily an indication that an animal can experience pain.

\section{Molluscs}

In a working article, Tonkins (2016) summarised the reasons why the Animal Health and Welfare Scientific Panel of the Europaen Food and Safety Authority (EFSA) decided to initiate legislation for the protection of cephalopods in scientific research. As a result, in 2013, an entire class of invertebrates comprising '... over 700 extant species (cuttlefish, squid, octopus and nautiloids) are protected from hatching (i.e. the eggs are not protected)'.
The essential conclusions were that cephalopods have higher brain centres and are likely to possess nociceptors and nervous pathways that connect them to the higher brain centres. In addition they show behavioural responses to pain and are likely to have receptors for opioids in the nervous system.

Guéry (2019:1) suggests that only three criteria are sufficient to demonstrate sentience in the octopus, explaining that behaviour when wounded, the presence of a central nervous system and behaviour under anaesthesia would suffice. Wounded octopi act as if they are in pain, and when an organism can feel pain, it is sentient. The nervous sytem of an octopus is very different from that of a vertebrate, but a central nervous system is in control, and octopi react to the same anaesthetic substances as humans.

Crabs and lobsters (Blackmore 2018):

When lobsters or crabs are injured, are taken out of water or have a claw twisted off, they release stress hormones similar to cortisol and corticosterone. This response provides a physiological reason to believe they suffer. An even more telling demonstration is that when injured prawns limp and rub their wounds, this behaviour can be reduced by giving them the same painkillers as would reduce our own pain. (p. 43)

Magee and Elwood (2013:358) reported that the key criteria to experience pain was present in the shore crab, Carcinus maenas, and stated that, '[t]hus multiple studies have had the potential to disprove the notion that invertebrates experience pain, and their results have been consistent with the notion of pain'.

\section{Insects}

Insects possess a centralised nervous system with ganglia and a small, simple brain. Griffin and Speck (2004:15), whilst reviewing the extensive research on the communicative skills of honeybees, agreed that based on published research evidence of reflective consciousness is lacking, but the case for perceptual conciousness in bees is strong.

\section{Vertebrates}

\section{Fish}

The term 'fish' is a catch-all phrase for a group of phylogenetically diverse vertebrates, including coelecanths, which are more closely related to humans than to barracudas. Barracudas, in turn, are more closely related to humans than to sharks. However, as a group, fishes are so extensively exploited by humans that approximately $90 \%$ of species in European waters are threatened with extinction and $40 \%$ of sharks face the same dilemma.

As worldwide concerns rise over the rape of our marine resources, a continuing debate has ensued in the scientific literature, concerning the possibility that fish are sentient and can experience pain, suffering and stress. 
Jonathan Balcombe, Director of Animal Sentience for The Humane Society Institute for Science and Policy, interviewed during 2016, on the television programme Fresh Air, revealed that ' $w$ ]e humans kill between 150 billion and over 2 trillion fish a year ... and the way they die - certainly in commercial fishing - is pretty grim...'.

It is commonly reported that a certain tonnage of fish has been harvested, subtly implying an equivalency with the harvesting of maize or wheat. The comparison to plants is unfortunate, because of the implication that pain or sentience play no role in these economic activities.

The subject of fish sentience, therefore, has moral as well as economic implications for humans because, if conclusively proved, governments face a moral burden when considering legal restrictions or outright prohibition in the utilisation of living natural resources. This could affect the economic future of the responsible agents and employees in the fishing industry on a worldwide scale. In addition, if consumers take to heart the fact that fish do indeed suffer because of current international fishing methods, they might be aversely influenced against the consumption of fish as a healthy food.

It is a sad fact of life that discrepancies exist between the promulgation and implementation of protective measures to safeguard species. A case in point is that, based on evidence, both the critically endangered Southern Atlantic bluefin tuna and the Patagonian toothfish experience pain (Sneddon, Wolfenden et al. 2018:5), but proposals to list these, and other species, on Convention on International Trade in Endangered Species of Wild Fauna and Flora (CITES) fails for political reasons. Manipulating classification procedures because of economic value thus leave endangered species and species that are accepted to experience pain, unprotected. Jacquet (2018:3) accordingly remarked that this was a case where 'seafood trumps sentience'.

Prevalent amongst some scientists has been the conviction that mammalian consciousness is associated with the neocortex and, in animals which lack this structure, consciousness is absent.

According to Key (2016:1) '... fish lack the necessary neurocytoarchitecture, microcircuitry, and structural connectivity for the neural processing required for feeling pain'. Thus, according to Key, fish do not have the required neural pathways. He, therefore, rejects all behavioural and physiological evidence and relies solely on anatomy to uphold the uniqueness of humans and asserts that fish do not feel anything like pain.

Statements like the above appear naive, as the structure of the vertebrate brain has essentially remained unchanged since the evolution of sharks, save for the proportional evolution and relative contribution of its constituent parts. The belief that fishes do not feel pain, ignores the fact that many animals, including fishes, lacking a neocortex do experience pain and distress.

Woodruff (2017:14) argued that the anatomy of the brain and the nerves connecting to the palliun in fishes are suffciently intricate to approximate the nervous connections of the cortex and thalamus, which is assumed to underlie sentience in mammals. In other words, fish are sentient.

In vertebrates the pallium consists of grey and white matter and covers the upper surface of the cerebrum. In mammals the cortical portion of the pallium develops into the cerebral cortex. Brain research in fishes have shown that '... at least minimal sentience is possible without a neocortex ...' and that the optic tectum plays '.. a role in the generation of sentience ...' (Woodruff 2017:2). (See Woodruff 2017 for an in-depth discussion.) 'In addition, brain gene expression studies demonstrate that similar "pain" genes are involved' (Sneddon, Wolfenden et al. 2018:3). In conjunction to neurobiological data, information on behaviour further supports the hypothesis that fishes have the capacity for sentience (Sneddon, Wolfenden et al. 2018:11). According to Blackmore (2018):

When researchers injected the lips of rainbow trout with acetic acid, the fish rocked from side to side and rubbed their lips on the side of the tank and on the gravel, but giving them morphine reduced these reactions. When Zebra fish were given a choice between a tank with gravel and plants and a bare one, they chose the interesting tank. But if they were injected with acid and the barren tank contained a painkiller, they swam to the barren tank instead. Fish pain may be simpler or in other ways different from ours, but these experiments suggest they do feel pain. (p. 43)

Acknowledging fish sentience and pain would not only benefit humans, as has been shown in terrestrial animal production, but would also benefit countless sentient creatures, whose pain is currently being denied. 'To state the obvious: if an animal looks like it's in pain, assume it is, until the contrary is empirically demonstrated' (Sneddon, Wolfenden et al. 2018:3).

\section{Woodruff (2017) stated that:}

[A] review of neuroanatomical, neurophysiological and behavioural studies is presented which leads to the conclusion that fish do have neurobiological correlates and behavioral flexibility of sufficient complexity to support the hypothesis that they are capable of phenomenal consciousness. (p. 1)

In other words the brain of ray-finned fishes are sufficiently complex to support sentience (Sneddon, Wolfenden et al. 2018):

We would like to add that A delta fibres in fish are polymodal; they respond to the same stimuli as mammalian $C$ fibres but conduct faster due to the myelin sheath.... (p. 3)

In addition, 'brain gene expression studies in fish demonstrate that similar "pain" genes are involved ...' (Sneddon, Wolfenden et al. 2018:3). A delta fibre, associated with fast, sharp pain, and C-fibres, associated with slow, burning pain, 
are present in the trigeminal nerve of trout, indicating that fish do experience pain. Woodruff (2018:2) concurrs and points out that studies on the peripheral nociceptors in the tail and body of fish '... show that the nociceptive input reaches the telencephalon, including the pallium'. Thus '... the complexity of neurophysiological activity from peripheral nerves to the pallium supports the argument by Sneddon, Wolfenden et al. (2018) that fishes constantly experience pain':

Recent advances in our understanding of the complexity of their behaviour, physiology and neurobiology have suggested that fish and other aquatic species are far from being just reflexive automata. Indeed, they meet Broom's (2007:100) criteria for sentience, including the ability to experience positive and negative emotions. (p. 3)

Woodruff (2018:15) agrees that the existing evidence is explicit enough to conclude that there is, after all, something it feels like to be a fish.

\section{Amphibians and reptiles}

Frogs are extensively utilised in scientific research and the culinary industry all over the world. As with other non-mammal species doubt has been expressed about their cognitive abilities, and whether they experience pain. Sneddon et al. (2014:201-212) positively summarised evidence that show the presence in Amphibia and Reptilia of, amongst other attributes, nociceptors, receptors for analgesic drugs, ability to move away from noxious stimuli, neural pathways to the central nervous system and central processing in the brain. To all intents and purposes then, frogs and reptiles are sentient. They point out that '... amphibians and reptiles share with mammals an opioid and endogenous opioid system involved in pain mechanisms' (Sneddon et al. 2014:206). In addtion, they advocate applying the precautionary principle when contemplating protection for a particular species, as it comprises (Sneddon et al. 2014):

[T] he idea that it is better to err on the side of more protection for a group of animals if it is beyond reasonable doubt that they experience pain .... (p. 209)

\section{Birds}

With regard to birds, Emery (2005:34) pointed out that the traditional view that '.. the six-layered neocortex of most mammals is the prerequisite for complex cognition still pervades popular culture'. The avian brain was, therefore, relegated to a lesser status. According to Emery (2005):

$[O]$ ne reason for this long-held, but ultimately incorrect view is the confusing terminology used to name the different regions of the avian telencephalon (forebrain). Traditionally regions in the avian cerebrum ended in the suffix - striatum, meaning derived from the basal ganglia ... As the vertebrate basal ganglia is involved in species-specific behaviors, such as maternal care, sexual behavior and feeding ..., bird-brains were deemed incapable of producing flexible or intelligent behaviour. It is now known that this nomenclature is based on a fallacy; large parts of the avian forebrain are derived, not from the striatum, but from the pallium ... Interestingly, the mammalian neocortex is also derived from the pallium ... This places the avian forebrain into a new light, where bird behavior may now be explained as an adaptation to solving socio-ecological problems similar to mammals, possessing hardware that is different to mammals, albeit evolved from the same structure. (p. 34)

Avian behaviour can therefore be explained in a similar way to that of mammals (Emery 2005):

Some families, such as the corvids and parrots, appear to have evolved superior cognitive abilities compared to other birds, and which in many cases can be compared favourably to the great apes. (p. 36)

This explains why some corvids (crows) share many of the intellectual attributes of non-human primates. The reason for this appears to be the fact that corvids and parrots experience many of the same ecological challenges as do primates.

Finally, Emery (2005:38) reminds the comparative psychologists that they do not have to secure exotic bird species in order to study complex cognition in birds, because there are already 'feathered apes in your garden'.

\section{Mammals}

De Waal (2019:239) notes that if somebody enquires if he thinks elephants are conscious beings, he sometimes counters with, '[y]ou tell me what consciousness is, and I'll tell you if elephants have it'. He acknowledges the unfairness of his answer, because he is convinced that elephants are conscious. He and his team were the first to show that elephants recognise themselves in a mirror.

'Mirror self-recognition (MSR) is exceedingly rare in the animal kingdom' (Plotnik, De Waal \& Reiss 2006:17053). It is regarded as a sign of self-awareness and was long thought to be restricted to apes and humans. 'In both phylogeny and human ontogeny MSR is thought to correlate with higher forms of empathy and altriustic behavior' (Plotnik et al. 2006:17053).

Frans De Waal and his team (Plotnik et al. 2006) were the first to experimentally show that the Asian elephant, Elephas maximus, can recognise itself in a large elephant-resistant mirror. The elephants were marked about the head with an easily discernable white cross and their reactions in front of the mirror recorded. They recognised themselves and used the mirror to closely inspect their bodies and the marks. 'Elephants have the advantage that they can touch most of their own bodies with their trunks, thus permitting an unequivocal mark test' (Plotnik et al. 2006:17053). This behaviour is interpreted as a sign of self-awareness.

Game wardens observing elephant behaviour over time have repeatedly reported that they seem to form close, reciprocal, intraspecific connections by choice. This behaviour has all the earmarks of friendship and emotional attachment, supported by the fact that in situations, like the death of a friend, which we experience as emotionally 
stressful, elephants likewise show signs of intense emotional reaction and high levels of distress.

In testing cooperative skills amongst Asian elephants, De Waal (2019:239) points out that they do as well as apes and better than most animals. In Thai or Indian villages bells are suspended from the necks of young elephants so that they do not inadvertently surprise the inhabitants in their gardens or kitchens. In response the elephants sometimes stuff grass in the bells to dampen the sound and walk around undetected (De Waal 2019):

This solution suggests imagination, because certainly no one showed them how to do this, and grass doesn't accidently get inside bells for them to discover its effect. To come up with clever solutions, we humans consciously put cause and effect together in our heads. If this is how we do it, why would elephants have a shortcut to problem solving sans consciousness? (pp. 239-240)

As with humans and apes, dolphins and especially elephants are well known for exhibiting empathy and altruistic behaviour. Reiss and Marino (2001) reported MSR in the bottlenose dolphin, Tursiops truncatus, and pointed out that this capacity does not emerge definitely in humans until the age of 19-24 months, ' $\ldots$ and marks the beginning of a developmental process of achieving increasingly abstract psychological levels of self-awareness, including introspection and mental state attribution' (Reiss \& Marino 2001:5937).

At the time these experiments offered the first conclusive evidence that non-primate species such as the bottlenose dolphin is capable of MSR (Reiss \& Marino 2001):

Bottlenose dolphins share several behavioral and social ecological features with great apes and humans, including sophisticated memory and classification of relationships among events ... the ability to learn rudimentary symbol-based artificial codes ... and complex social behaviour ... Bottlenose dolphins, great apes, and humans all possess high degrees of encephalization and neocortical expansion ... Yet the brains of dolphins are markedly different from those of primates on many levels, including cortical cytoarchitecture and organization ... reflecting the fact that the cetacean (dolphin, whale, and porpoise) and primate ancestral lines diverged at least 60-70 million years ago. (p. 5942)

The findings by Reiss and Marino (2001):

[S]how that self-recognition may be based on a different neurological substrate in dolphins. More generally, these results represent a striking case of cognitive convergence in the face of profound differences in neuroanatomical characteristics and evolutionary history. (p. 5942)

\section{Non-human primates}

Anthropologists attempt to answer questions about what it means to be human, by studying both the fossil remains of our ancestors and the behaviour of our nearest living ancestors, the non-human primates. Consequently, some researchers have surmised that human laughter is a paradox, a uniquely human feature, setting us apart from our ancestors and primate relatives. 'Laughter shows how central the body is to our existence, including our mental health. Laughter brings body and mind together, fusing them to a single whole' (De Waal 2019), and:

[L]aughter is one of the great joys of being human, with wellknown health benefits, such as stress reduction, stimulation of heart and lungs, and release of endorphins. Nevertheless we should hope that extraterrestrials never get to watch a group of out-of-control laughing humans, because they'd probably abandon the idea of having found intelligent life. (p. 69)

However, laughing behaviour is not restricted to humans as a gorilla mother will tickle the belly of her baby, a few days after birth, causing its first laugh (De Waal 2019:73). More to the point, Panksepp and Burgdorf (2003:535) have discovered that rats 'laugh' when regularly tickled in the same way by a human, and that they actively seek out stimuli of this kind. During these play-and-tickle sessions, rats emit ultrasonic chirps of approximately $50 \mathrm{kHz}$ that may resemble primitive human laughter (Panksepp \& Burgdorf 2003):

Whether there are fundamental neural homologies to be found between the 'laughing' response of rodents and the playful laughter of human children remains to be assessed using neurological and genetic tools. (p. 545)

Further research holds the promise that '... a detailed analysis of the underlying neurobiological controls may highlight important commonalities between tickle-induced chirping in young rodents and youthful laughter in the human species' (Panksepp \& Burgdorf 2003:545).

Taking the long view in terms of vertebrate evolution it seems counter-intuitive that we possess characteristics that are not, at least, incipiently present in non-human primates or other mammals. Logothetis (1999) reported that:

$[M]$ onkey brains are organised like those of humans, and they respond to stimuli, much like humans do. Consequently, we think the animals are conscious in somewhat the same way as humans are. (p. 70)

De Waal (2019:252) favoured the existence of episodic memory in wild chimpanzees, because amongst the multitude of trees in the forest, their daily foraging visits are restricted to selected fruit-bearing trees in a non-random way. In the Taï forest chimpanzees appear to plan ahead, calculating early morning departure times to remember fruit sources, based on distance to travel in order to arrive first.

In the Sumatran rain forests, dominant orangutan males are known for similar behaviour. Their vociferous calls, high up in the trees, are audible over extensive areas of rain forest, and before a dominant male retires for the night, he will loudly call in the specific direction he intends to travel the following day. In this way his conspecific audience are informed of his intentions, about $12 \mathrm{~h}$ before he sets off (De Waal 2019:225). 
At the Furuvik Zoo in Gävle, Sweden, a chimpanzee named Santino started pelting visitors with rocks. It turned out that, hours prior to the arrival of visitors, Santino would hide these missiles under logs and strategically placed bundles of hay, prompting investigators to suspect that he was engaging in mental time travel, that is, imagining his future actions and thus 'living life autobiographically, with a sense of one's own story' (Keim 2017:33).

Throughout his career Frans de Waal (2019:45) has consistently supported the concept of cognition in primates and other mammals. Recently, however, he expressed reservations about the possibility of incipient ethical behaviour in the newly discovered hominin, Homo naledi, discovered in the Dinaledi Chamber of the Rising Star cave complex in South Africa (Berger et al. 2015). Dirks et al. (2016) hypothesised that the remains were secreted in the cave system by conspecifics and that it might be indicative of the first stirrings of ethical behaviour and cognition in Homo. Deliberately avoiding value-laden terms associated with ritual burials, they chose to interpret the accumulation of skeletal remains as an instance of deliberate disposal. Amid criticism from various quarters, additional material of $H$. naledi from the Lesedi Chamber of the cave system (Hawks et al. 2017) has substantiated the deliberate disposal hypothesis. Du Toit (2017:1) had provisionally accepted the hypothesis and, with reference to Broca's area in australopithecines, hypothesised an enlarged Broca's area in $H$. naledi '... suggesting the possibility of a sophisticated communication system and an enhanced way of dealing with emotion'.

Based on his extensive work with primates, De Waal is sceptical of the claims made about $H$. naledi, but his alternative suggestion that the remains were left in the cave as a practical method of getting rid of the corpses, which may have attracted predators, seems inadequate against the extremely difficult and tortuous route of getting that deep in the cave system. A far more practical move would have been just to abandon the corpses as the band moved on. It would seem that the immense effort just to place the bodies in such a secluded and secure subterranean locality would argue in favour of the deliberate disposal hypothesis and the incipient emergence of conciousness in hominins.

De Waal also entertains the notion that we do not even know if these individuals were actually dead when they were deposited in the cave. Again the tortuous route and the sheer exertion to reach the depths of the various chambers in which the bodies were deposited make this kind of speculation highly unlikely. Berger (pers. comm. January 2020, University of the Witwatersrand) is cautious about premature claims, but in the light of ongoing research, it seems that additional evidence for the initial claims about deliberate disposal may indeed be in the offing.

\section{The mammalian brain}

It is often still said that the mammalian brain is divided into three constituent parts: (1) The brain stem or the so-called reptilian brain, inherited from our evolutionary past, (2) the middle portion that evolved in mammals to act as a brake on the instinctive behaviour initiated by the brain stem and (3) the cortex or neocortex as the signature development of mammals.

However, Naumann and Laurent (2017:493) is convinced that such a division is too simplistic and stark, that in reality the relationship is much more complicated and that the transition between the different components is much more gradual and overlapping. This supports the position that a neocortex is not essential for the basic appearance of cognition and sentience.

The neocortex (also neopallium and isocortex) is embryologically derived from the dorsal telencephalon, the front portion of the forebrain, and is the most recently evolved component of the mammalian brain. Found only in mammals, it is universally accepted that it consists of six layers of neural tissue (Beck 2008:143). 'The neocortex is the part of the brain responsible for the execution of higher order brain functions, including cognition, sensory perception and sophisticated motor control' (Lodato \& Arlotta 2015:699).

As a subsystem of the cerebral cortex it comprises the frontal, parietal, occipital and temporal lobes. Formed by grey matter, also known as neuronal cell bodies, and unmyelinated nerve fibres, it covers the inner cerebral layers of white matter consisting of myelinated axons. In humans the neocortex forms $90 \%$ of the cerebral cortex and $76 \%$ of the entire brain.

In primates and larger mammals the neocortex is convoluted, presenting a pattern of deep grooves (sulci) and ridges (gyri), which greatly increases the surface area. In contrast the neocortex of smaller mammals is smooth.

It has been postulated that we will not be able to fully understand animal consciousness, unless the mystery of human consciousness has been satifactorily explained. It is manifestly obvious that significant progress is being made in this theatre of research, as is evinced by the continuing stream of books and articles on the subject. In one of the current contributions on the subject, Huang et al. (2020) have proposed that:

[E]vidence from noninvasive functional neuroimaging studies has pointed to two distinct cortical systems that support consciousness. The default mode network (DMN) is an internally directed system that correlates with consciousness of self, and the dorsal attention network (DAT) is an externally directed system that correlates with consciousness of the environment. The DMN engages in a variety of internally directed processes such a autobiographical memory, imagination, and self referencing. The DAT, on the other hand, mediates externally directed cognitive processes such as goaldriven attention, inhibition, and top-down guided voluntary control. (p. 1) 
The fact that these two systems are not simutaneously active, 'appear to be in a reciprocal relationship with each other ...' (Huang et al. 2020:1). This phenomenon suggests that the two systems are '... anticorrelated. This anticorrelation is presumed to be vital for maintaining an ongoing interaction between self and environment that contributes to consciousness' (Huang et al. 2020:1):

This study suggests that human consciousness relies on a specific temporal circuit of dynamic brain activity characterized by balanced reciprocal accessibility of functional brain states. The disruption of this temporal circuit, exhibiting limited access to the DMN and DAT, appears to be a common signature of unresponsiveness of diverse etiologies. (p. 9)

This research outcome may be regarded as a small step in the eventual resolution of the mystery of human consciousness and in so doing reveals further avenues of research in animal sentience.

Finally, Broom (2007:105) had pointed out that sentience consisted of a variety of abilities, which included certain cognitive abilities as well. Sentient beings, therefore, have some ability (Broom 2007):

$[T]$ o evaluate the actions of others in relation to itself and third parties, to remember some of its own actions and their consequenses, to assess risks and benefits, to have some feelings, and to have some degree of awareness. (p. 100)

There is, according to Broom (2007):

[E]vidence from some species of fish, cephalopods and decapod crustaceans of substantial perceptual ability, pain and adrenal systems, emotional responses, long- and short-term memory, complex cognition, individual differences, deception, tool use and social learning. The case for protecting these animals would seem substantial. (p. 105)

In an extended overview and summary of animal minds, Keim (2017) remarked that:

$[M]$ uch of what is so important in our own lives - memories, emotions, relationships, the daily experience of making plans and solving problems - is found all around us, and not just in obviously brainy creatures like chimpanzees or dolphins or crows, but even in songbirds and fish and insects. Our experience of the world is far richer for it. We live in a world of minds. Only some of them are human. (p. 5)

\section{Conclusion}

Neurobiologists, behaviourists and anatomists, each in their own way, are chiseling away at the mystery of conciousness and increasingly revealing the shared, hidden depths of animal sentience. Based on current knowledge of the phenomenon, it is clear that it evolved in accordance with Darwinian principles, is widely distributed amongst living entities in various guises, from simple to complex, and that fully formed language is not a prerequisite for its presence. Humans are, therefore, not the only conscious organisms on the planet, as suggested by a variety of research results, attesting to the fact that even lower vertebrates possess sentience and feel pain.
Recognising consciousness as a biological heritage will necessitatecasting off the constrictive coils of anthropocentrism in favour of the realisation that animal sentience share a common origin with human consciousness and should influence our thinking about, and dealings with, the living world in terms of respect, suffering and cognition in general. Such an approach should include a defensible moral position with regard to the economic usage and treatment of life forms we aggressively utilise as food items on such a massive scale.

Accepting the validity of these empirical findings impinges strongly on traditional theological dogma and is tantamount to a paradigm shift in theological thinking. Traditionally, theology has claimed the moral high ground in many things. To now cede that position and acknowledge the veracity of scientific knowledge, especially evolutionary biology, represents a moral watershed with profound theological implications. However, there does appear to be some light at the end of the tunnel, insofar as some theologians are incipiently advocating that traditional theology undergo a 'greening' transformation in which they unequivocally and responsibly acknowledge our dependance on and close relationship with all life, as well as planet earth.

\section{Acknowledgements Competing interests}

The authors declare that they have no financial or personal relationships that may have inappropriately influenced them in writing this research article.

\section{Authors' contributions}

J.v.d.H. and C.J. contributed equally to the writing of this research article.

\section{Ethical considerations}

This article followed all ethical standards for research without direct contact with human or animal subjects.

\section{Funding information}

This research received no specific grant from any funding agency in the public, commercial or not-for-profit sectors.

\section{Data availability}

Data sharing is not applicable to this article as no new data were created or analysed in this study.

\section{Disclaimer}

The views and opinions expressed in this article are those of the authors and do not necessarily reflect the official policy or position of any affiliated agency of the authors. 


\section{References}

Allan, C. \& Trestman, M., 2017, 'Animal consciousness', in E.N. Zalta (ed.), The Stanford Encyclopedia of philosophy, viewed 06 September 2020, from https://plato. stanford.edu/archives/win2017/entries/consciousness-animal/.

Beck, F., 2008, 'Synaptic quantum tunneling in brain activity', NeuroQuantology 6(2), 140-151. https://doi.org/10.14704/nq.2008.6.2.168

Berger, L.R., Hawks, J., De Ruiter, D.J., Churchill, S.E., Schmid, P., Delezene, L.K. et al., 2015, 'Homo naledi, A new species of the genus Homo from the Dinaledi Chamber, South Africa', ELife 4, 1-35. https://doi.org/10.7554.eLife.09560.00

Blackmore, S., 2018, 'Decoding the puzzle of human consciousness: The hardest problem', Scientific American 319(3), 41-45.

Broom, D.M., 2007, 'Cognitive ability and sentience: Which aquatic animals should be protected?', Diseases of Aquatic Organisms 75, 99-108. https://doi.org/10.3354/ dao075099

Chomsky, N., 1976, 'Problems and mysteries in the study of human language', in A. Kasher (ed.), Language in focus: Foundations, methods, and systems, Bosto studies in the philosophy of science, vol. 45, pp. 281-357, Springer, Dordrecht.

Chomsky, N., 2014, Mysteries and problems, YouTube, viewed 18 October 2020, from https://www.youtube.com/watch?v=G8G2QUK-1wg.

Crick, F. \& Koch, C., 1998, 'Consciousness and neuroscience', Cerebral Cortex 8(2), 97-107. https://doi.org/10.1093/cercor/8.2.97

Damasio, A., 1999, The feeling of what happens: Body and emotion in the making of conscipousness, Harcourt, New York, NY.

Dawkins, M.S., 1980, Animal suffering: The science of animal welfare, Chapman \& Hall, London.

Dennett, D.C., 1993, Conciousness explained, Penguin Books, London.

Dennett, D.C., 2018, From bacteria to bach and back: The evolution of minds, Penguin Books, London.

De Waal, F., 2019, Mamma's last hug: Animal emotions and what they teach us about ourselves, Granta Publications, London.

Dirks, P.H.G.M., Berger, L.R., Hawks, J., Randolph-Quinney, P.S. \& Backwell, L.R., 2016 'Deliberate body disposal by hominins in the Dinaledi Chamber, Cradle of Humankind, South Africa', Journal of Human Evolution 30, 1-5. https://doi. org/10.1016/j.jhevol.2016.04.007

Duncan, I.J.H., 2006, 'The changing concept of animal sentience', Applied Animal Behaviour Science 100, 11-19. https://doi.org/10.1016/j.applanim.2006.04.011

Du Toit, C.W., 2017, 'Has evolution "prepared" us to deal with death? Paleoanthropological aspects of the enigma of Homo naledi's disposal of their dead', HTS Teologiese Studies/Theological Studies 73(3), a4047. https:/doi. org/10.4102/hts.v73i3.4074

Edelman, G.M., 2003, 'Naturalising consciousness: A theoretical framework', Proceedings of the National Academy of Sciences USA 100, 5520-5524. https:// doi.org/10.1073/pnas.0931349100

Emery, N.J., 2005, 'Cognitive ornithology: The evolution of avian intelligence', Philosophical Transactions of the Royal Society B 361, 23-43. https://doi. org/10.1098/rstb.2005.1736

Griffin, D.R. \& Speck, G.B., 2004, 'New evidence of animal consciousness', Animal Cognition 7, 5-18. https://doi.org/10.1007/s10071-003-0203-x

Gross, C.G., 2009, 'Early steps toward animal rights', Science 324, 466-467. https:// doi.org/10.1126/science.1173236

Guéry, A.N., 2019, 'Octopus sentience: Three criteria', Animal Sentience 279, 1-3. https://doi.org/10.4324/9781315647791-26

Hawks, J., Elliot, M., Schmid, P., Churchhill, S.E., De Ruiter, D.J., Roberts, E.M. et al., 2017, 'New fossil remains of Homo naledi from the Lesedi Chamber, South Africa', ELife 6, e24232. https://doi.org/10.7554/eLife.24232

Huang, Z., Zhang, J., Wu, J., Mashour, G.A. \& Hudetz, A.G., 2020, 'Temporal circuit of macroscale dynamic brain activity supports human consciousness', Science Advances 6, 1-14. https://doi.org/10.1126/sciadv

Jacquet, J., 2018, 'Defining denial and sentient sea food', Animal Sentience 21(8), 1-4.

Keim, B., 2017, Inside animal minds: What they think feel and know, National Geographic, Washinton, DC
Kenny, A., 1997, The Oxford illustrated history of western philosophy, Oxford University Press, Oxford.

Key, B., 2016, 'Why fish do not feel pain', Animal Sentience 3(1), 1-33.

Leroi, A., 2014, The lagoon: How Aristotle invented science, Viking, New York, NY.

Lodato, S. \& Arlotta, P., 2015, 'Generating neuronal diversity in the mammalian cerebral cortex', Annual Review of Cell and Developmental Biology 31, 699-720. https://doi.org/10.1146/annurev-cellbio-100814-125353

Logothetis, N.K., 1999, 'Vision: A view on consciousnes', Scientific American 281(5), 68-75. https://doi.org/10.1038/scientificamerican1199-68

Magee, B. \& Elwood, R.W., 2013, 'Shock avoidance by discrimination learning in the shore crab (Carcinas maenas) is consistent with a key criterion for pain', The Journal of Experimental Biology 216, 353-358. https://doi.org/10.1242/ jeb.072041

Margulis, L., 2001, 'The conscious cell', Annals of the New York Academy of Sciences 929(1), 55-70. https://doi.org/10.1111/j.1749-6632.2001.tb05707.x

McGinn, C., 1991, The problem of consciousness: Essays towards a resolution, Blackwell, Cambridge, MA.

Montalenti, G., 1974, 'From Aristotle to Democritus via Darwin: A short history of a long historical and logical journey', in F.J. Ayala \& T. Dobzhansky (eds.), Studies in the philosophy of biology: Reduction and related problems, pp. 3-19, University of California Press, Berkeley.

Nagel, A.H.M., 1997, 'Are plants conscious?', Journal of Consciousness Studies 4(3), 215-230.

Natsoulas, T.N., 1983, 'Concepts of consciousness', Journal of Mind and Behaviour $4(1), 13-59$.

Naumann, R.K. \& Laurent, G., 2017, 'Function and evolution of the reptilian cerebral cortex', in J. Kaas (ed.), Evolution of nervous systems, vol. 1, 2nd edn. pp. 491-518, Academic Press, Cambridge, MA.

Panksepp, J. \& Burgdorf, J., 2003, “'Laughing” rats and the evolutionary antecedents of human joy', Physiology and Behaviour 79(3), 533-547. https://doi.org/10.1016/ S0031-9384(03)00159-8

Pinker, S., 2011, The better angels of our nature: A history of violence and humanity, Penguin Books, London.

Plotnik, J.M., De Waal, F.B.M. \& Reiss, D., 2006, 'Self-recognition in an Asian elephant', Proceedings of the National Academy of Sciences USA 103(45), 17053-17057. https://doi.org/10.1073/pnas.0608062103

Reiss, D. \& Marino, L., 2001, 'Mirror self-recognition in the bottlenose dolphin: A case of cognitive convergence', Proceedings of the National Academy of Sciences USA 98(10), 5937-5942. https://www.pnas.org/cgi/doi/19.1073/pnas.101086398.

Searle, J.R., 2000, 'Consciousness', Annual Review of Neuroscience 23, 557-578. https://doi.org/10.1146/annurev.neuro.23.1.557

Shapiro, J.A., 2011, Evolution: A view from the 21st century, FT Press Science, Upper Saddle River, NJ.

Sneddon, L.U., Elwood, R.W., Adamo, S.A. \& Leach, M.C., 2014, 'Defining and assessing animal pain', Animal Behaviour 97, 201-212. https://doi.org/10.1016/j. anbehav.2014.09.007

Sneddon, L.U., Lopez-Luna, J., Wolfenden, D.C.C Leach, M.C Valentim, A.M Steenbergen, P.J. et al., 2018, 'Fish sentience-denial: muddying the waters', Animal Sentience 21(1), 1-11.

Sneddon, L.U., Wolfenden, D.C.C., Leach, M.C., Valentim, A.M., Steenbergen, P.J., Bardine, P.J. et al., 2018, 'Ample evidence for fish sentience and pain', Animal Sentience 21(17), 1-7.

Tonkins, B.M., 2016, Why are cephalopods protected in science in Europe, Research Gate.

Van den Heever, J. \& Jones, C., 2019, 'The evolution of morality', in J. Van den Heever $\&$ C. Jones (eds.), Moral issues in the natural sciences and technologies, pp. 1-26, AOSIS, Cape Town.

Woodruff, M.L., 2017, 'Consciousness in teleosts: There is something it feels like to be a fish', Animal Sentience 13(1), 1-21.

Woodruff, M.L., 2018, 'Pain in fish: Evidence from peripheral nociceptors to pallial processing', Animal Sentience 21(2), 1-3. 